\title{
Comparative Study of Self-Compacting Concrete with Manufactured and Dune Sand
}

\author{
Leila Zeghichi, Zeid Benghazi and Laid Baali \\ Department of Civil Engineering, Faculty of Technology, University of M'sila, M'sila 28000, Algeria
}

\begin{abstract}
Sand is an inert element essential in the composition of concrete; its use ensures granular continuity between the cement and gravel for better cohesion of concrete. This paper presents the results of a study that investigated the influence of sand quality on the properties of fresh and hardened SCC (self-compacting concrete). The dune sands are very fine materials characterized by a high intergranular porosity, high surface area and low fineness modulus; on the other hand crushed (manufactured) sand has a high rate into thin and irregular shapes which influence the workability of concrete. The amount of dune sand varies from $(0 \%, 50 \%$ to $100 \%)$ by weight of fine aggregates. The results show that the rheological properties favour the use of dune sands; however the mechanical properties support the use of crushed sand.
\end{abstract}

Key words: Self-compacting concrete, dune sand, crushed sand, flowability, segregation resistance.

\section{Introduction}

A SCC (self-compacting concrete) is a concrete that flows and sets up in the most complex and scrapped forms under the effect of its own weight. It is important to note that the material should not undergo any form of segregation and should have qualities similar to those of conventional vibrated concrete [1,2].

Aggregates are very important components of ordinary and self-compacted concretes (Fig. 1). It is well known that they affect both fresh and hardened concrete properties. Concrete flowability depends on the properties of cement paste, the amount and gradation of aggregates. The better flowability is obtained when the surface area is low [3].

The sand is the key component to ensure the granular continuity between the coarse aggregates (the gravel) and powders (cement and fillers). Crushed sands often require more water than round sands (obtained from dunes or rivers) to reach an aimed workability [4]. However, the round sands are characterized by a high intergranular porosity, which affect the aggregates

Corresponding author: Leila Zeghichi, senior lecturer, research fields: use of binders and durability of concrete. E-mail: zeghichi2004@yahoo.fr. packing and needs more powder to fill the voids and may increase the coast of SCC. The effect of round sand on mechanical properties of SCC is to be investigated.

The effect of crushed and round sands on the SCC is discussed here for both rheological and mechanical properties. The round sand used in this work is dune sand.

\section{Materials and Methods}

The physical properties and the chemical composition of the materials used are given in Tables 1-2 respectively. According to the particles size distribution (Fig. 2), it can be seen that the dune sand used in this work is fine (with a fineness modulus $M f=1.85$ ) and not entirely suitable to be used in concrete if a good strength is being looked for. For the crushed sand, $M f=2.1$, which may be considered as acceptable sand.

Two fillers are used, the lime stone powder and blast furnace slag. Their properties are given in Table 1.

According to the recommendations of The European Guidelines for Self Compacting Concrete [5], five mixtures are prepared in function of the nature and proportion of used sand, and the nature of filler used (Table 3). 

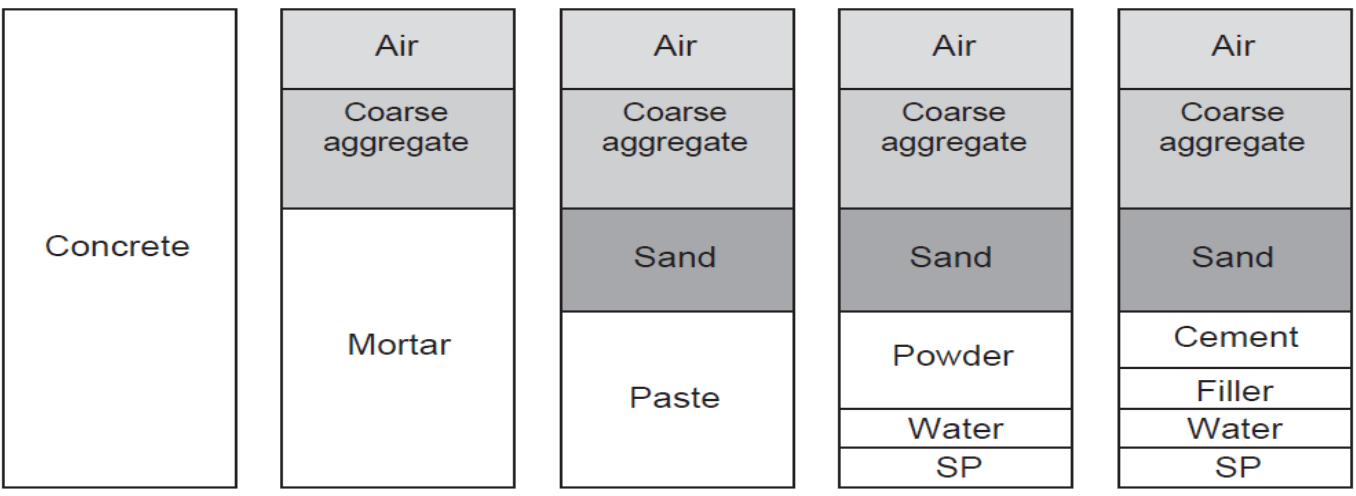

Fig. 1 Schematic composition of SCC [6].

Table 1 Physical properties of materials used.

\begin{tabular}{llll}
\hline Material & Type & $\rho\left(\mathrm{kg} / \mathrm{m}^{3}\right)$ & Blaine $\left(\mathrm{cm}^{2} / \mathrm{g}\right)$ \\
\hline Cement & CEM II/A 42.5 & 3,100 & 4,000 \\
Filler 1 & Limestone powder & 2,660 & 1,600 \\
Filler 2 & Blast furnace slag & 2,940 & 3,200 \\
Dune sand & Boussaada sand 0-3 & 2,540 & $/$ \\
Crushed sand & COSIDER quarry sand 0-3 & 2,530 & $/$ \\
Crushed gravel 1 & COSIDER quarry gravel 3-8 & 2,560 & $/$ \\
Crushed gravel 2 & COSIDER quarry gravel 8-16 & 2,550 & $/$ \\
Superplasticizer (liquid) & MEDAFLOW 30 (GRANITEX) & 1,070 & $/$ \\
\hline
\end{tabular}

Table 2 Chemical composition of materials used.

\begin{tabular}{lllllllll}
\hline Materials & $\mathrm{SiO}_{2}$ & $\mathrm{Al}_{2} \mathrm{O}_{3}$ & $\mathrm{CaO}$ & $\mathrm{Fe}_{2} \mathrm{O}_{3}$ & $\mathrm{MgO}$ & $\mathrm{SO}_{3}$ & $\mathrm{Na}_{2} \mathrm{O}$ & $\mathrm{Cl}^{-}$ \\
\hline Cement & 20.70 & 4.75 & 62.92 & 3.75 & 1.90 & 1.98 & 0.09 & 0.005 \\
Filler 1 & 10.81 & 0.31 & 47.51 & 0.76 & 0.21 & $/$ & $/$ & $/$ \\
Filler 2 & 40.80 & 5.20 & 43.01 & 0.53 & 6.40 & 0.80 & 0.01 & 0.007 \\
Dune sand & 86.95 & 1.92 & 6.33 & 0.09 & 0.53 & 0.44 & $/$ & $/$ \\
Crushed sand & 40.65 & 8.87 & 40.56 & 3.25 & 3.65 & 0.79 & 0.01 & $/$ \\
Crushed gravel & 40.65 & 8.87 & 40.56 & 3.25 & 3.65 & 0.79 & 0.01 & $/$ \\
\hline
\end{tabular}

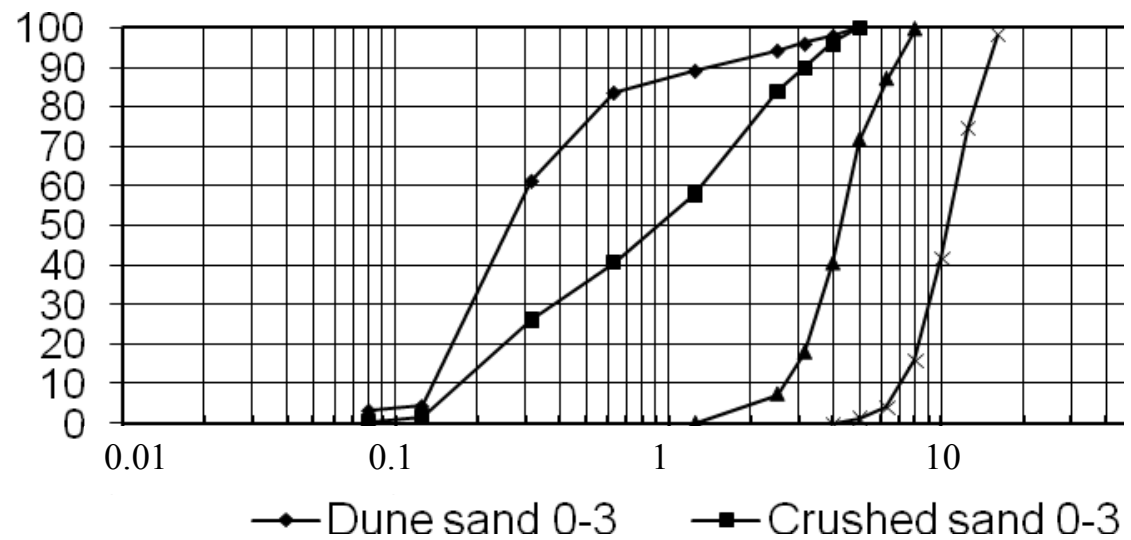

Fig. 2 Particles size distribution of used aggregates.

Table 3 Mix design for the experimental work.

\begin{tabular}{llllll}
\hline Factors & SCC 1 & SCC 2 & SCC 3 & SCC 4 & SCC 5 \\
\hline Dune sand & $100 \%$ & $100 \%$ & $50 \%$ & $50 \%$ & $0 \%$ \\
Crushed sand & $0 \%$ & $0 \%$ & $50 \%$ & $50 \%$ & $100 \%$ \\
Filler 1 & $0 \%$ & $100 \%$ & $0 \%$ & $100 \%$ & $0 \%$ \\
Filler 2 & $100 \%$ & $0 \%$ & $100 \%$ & $0 \%$ & $100 \%$ \\
\hline
\end{tabular}


In Table 3, Powder/Water $=0.40$ and Superplasticizer $/$ Powder $=1.2 \%$.

The mix composition of mixtures used is given in Table 4.

The experiments made on fresh concrete are:

- The passing ability (three bars L-box test);

- The flowability (slump-flow test using Abrams cone);

- The segregation resistance (sieve segregation resistance test).

All the experiments are done according to The European Guidelines for Self Compacting Concrete [5], based on the EN standards.

Compressive strength is measured for hardened concrete at 14. 28 and 45 days, using cubic specimens $(100 \times 100 \times 100 \mathrm{~mm})$. While tensile strength is measured at 28 days, by the Brazilian test on cylindrical specimens (Ø160 mm, height $320 \mathrm{~mm})$.

All specimens have been poured and conserved in molds for 24 hours, after that they have been removed from molds and immersed in water basin at a temperature of $20 \pm 2{ }^{\circ} \mathrm{C}$, until the time of test.

\section{Experimental Results on Fresh Concrete}

\subsection{Passing Ability}

Experiments show that Mixtures 1 and 2 (with 100\% of dune sand) give a high passing ratio, which means a good flowability of the SCC (Fig. 3). In the case of mixtures with $50 \%$ dune sand $/ 50 \%$ crushed sand, SCC 3 give higher passing ratio. These results are to be due to the round shape of dune sand particles as well as fineness of the filler used (SCC 1 and 3).

The fine dune sand used gives more flowability to the concrete. In the case of SCC 5 (with $100 \%$ of crushed sand) the flowing ability is very low, because of both the angular shape of crushed sand and the low fineness of the filler used (limestone powder).

As mentioned above, the use of a three bars L-box means that the passing ability class of the three first

Table 4 Mix composition of mixtures used.

\begin{tabular}{lllll}
\hline Component $\left(\mathrm{kg} / \mathrm{m}^{3}\right)$ & SCC 1 & SCC 2 & SCC 3 & SCC 4 \\
\hline Cement & 400 & 400 & 400 & 400 \\
Filler 1 & $/$ & 100 & $/$ & 100 \\
Filler 2 & 100 & $/$ & 100 & $/$ \\
Dune sand & 850 & 850 & 425 & 4 \\
Crushed sand & $/$ & $/$ & 425 & 425 \\
Crushed gravel 1 & 425 & 425 & 425 & 425 \\
Crushed gravel 2 & 425 & 425 & 425 & 425 \\
Water & 200 & 200 & 200 & 425 \\
Superplaticizer (liquid) & 6 & 6 & 6 & 200 \\
\hline
\end{tabular}

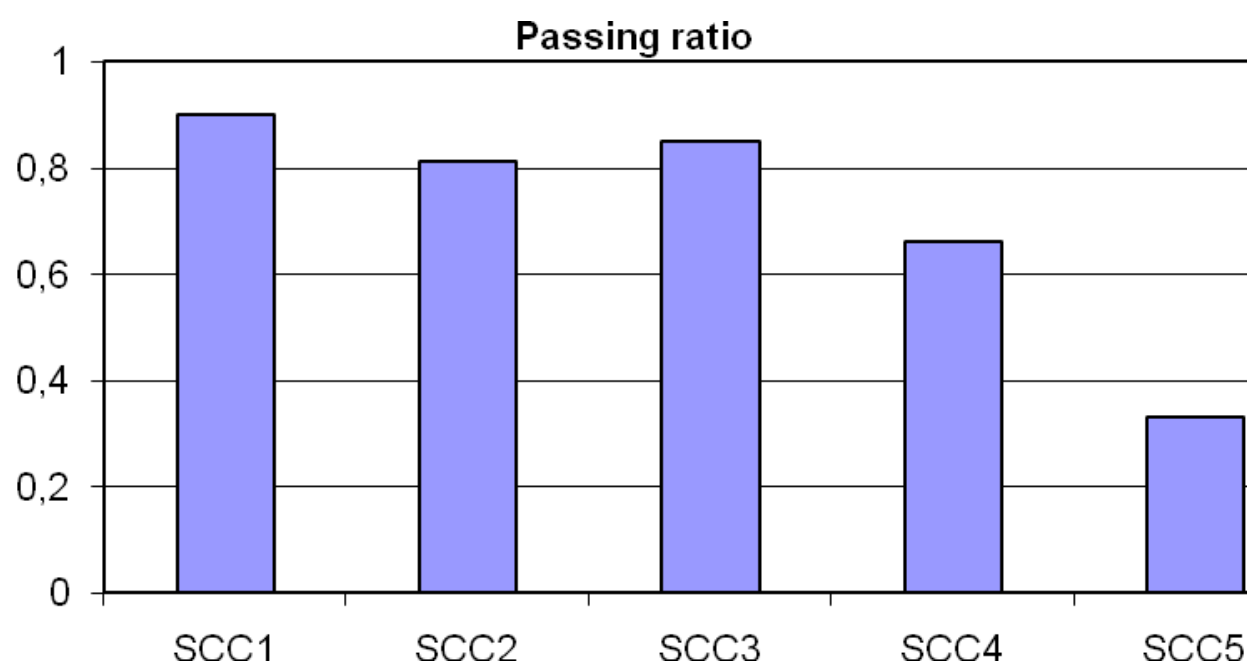

Fig. 3 Passing ratio for the different SCC mixtures using 3 bar L-box test. 
mixtures is PA2, which means that they have the ability to flow through structures with a gap of 60 to $80 \mathrm{~mm}$ (e.g., civil engineering structures) [5].

\subsection{Flowability}

According to the results shown in Fig. 4, only SCC 5 gives a low slump-flow. This may be due to the same reasons mentioned above for which it gives low passing ratio.

The slump flow of the other mixes can be classified as follows [5]:

- SF2 (660-750 mm) for SCC 2: Suitable for many normal applications;

- SF3 (760-850 mm) for SCC 1, 3 and 4: Suitable for vertical applications in very congested structures, structures with complex shape, or for filling under formwork.
These good results were obtained with a low amount of superplasticizer $(1.2 \%)$, while the ulterior studies showed that a high percentage is required to have a high fluidity $[7,8]$. This means that the high fluidity of the studied mixtures is due to the presence of round particles of dune sand. Spheres move easier than angular shape particles [9].

\subsection{Segregation Resistance}

All the mixtures prepared in this work show very high segregation resistance (Fig. 5). The segregation class of the prepared mixtures is SR $<15 \%$ [5]. The SCC 5 shows no segregation risks, for the same reasons of particles shape of crushed sand and the low fineness of the limestone powder used.

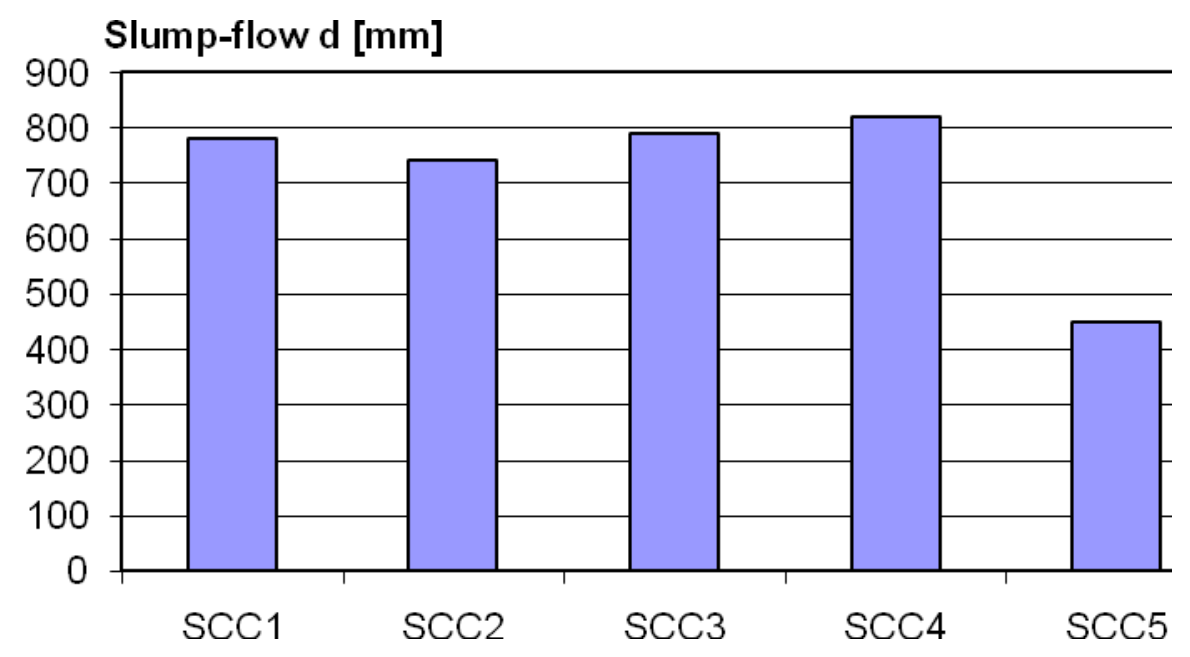

Fig. 4 Slump-flow for the different mixtures prepared.

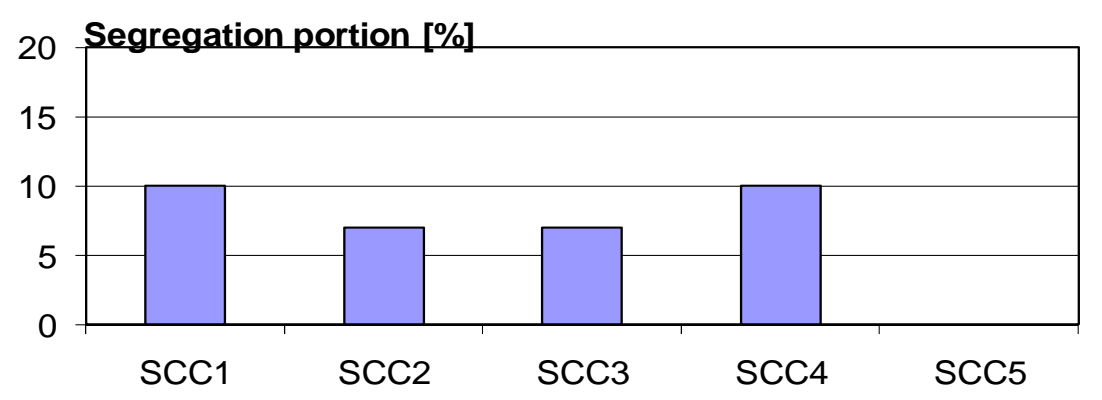

Fig. 5 Segregation proportion for the different mixtures prepared. 


\section{Experimental Results on Hardened} Concrete

\subsection{Compressive Strength $\left(f_{c}\right)$}

The compressive strength tests show that mixtures with $100 \%$ of dune sand give less strength than those with a partial substitution with crushed sand (50\%-50\%), which give a normal compressive strength (at 28 days) higher than $45 \mathrm{MPa}$ (Fig. 6).

The SCC 5 (100\% of crushed sand) gives a normal compressive strength near to SCC 1 (100\% of dune sand), which has the same filler used (granular slag powder).

The mixtures with granular slag powder as filler developed compressive strength quicker despite the nature of the sand used. This is because of the hydraulic nature of granular slag powder and its good fineness, forming additional C-S-H and increasing the concrete's strength [10].

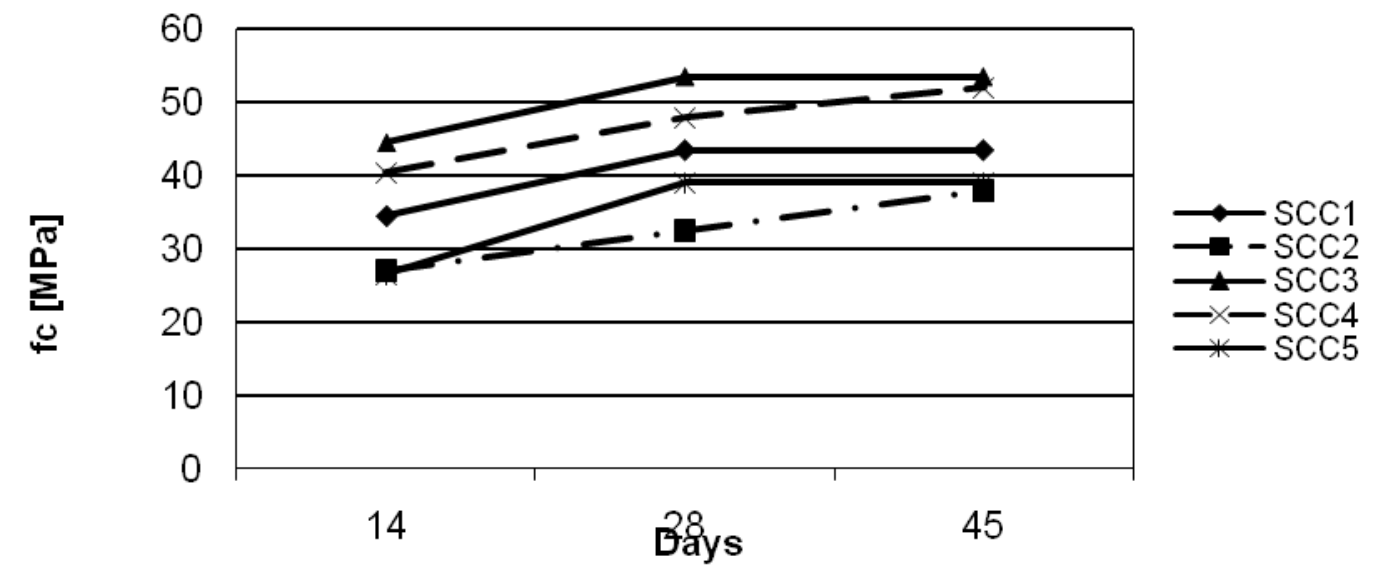

Fig. 6 Compressive Strength For The different mixtures.

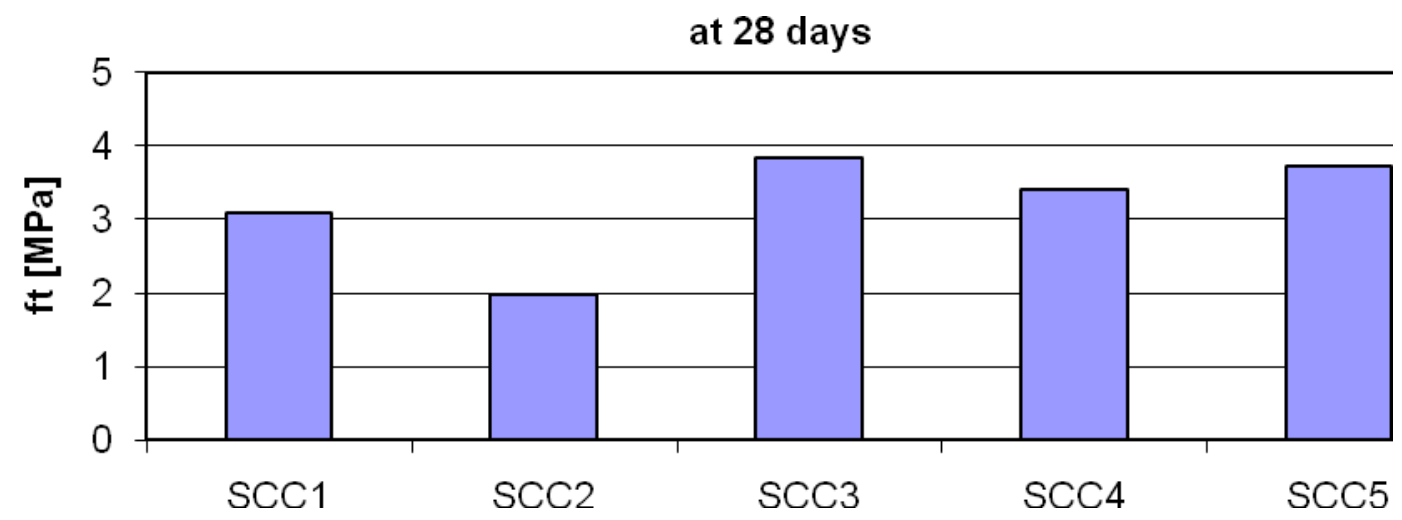

Fig. 7 Tensile strength for the different mixtures at 28 days. 
substitution of dune sand with crushed sand, despite the nature of addition. This means that the angular shape of crushed sand gives better adherence, packing and compatibility with the crushed coarse gravel.

\section{Conclusions}

This paper has focused on the physical effects of both dune (round) sand and crushed sand on the SCC.

Dune sand gives less viscosity and then better flowability to the SCC, due to its round shape which reduces the intergranular friction between sand particles themselves and between sand and gravel. Spheres move easier than angular shape particles [9].

This makes the particles interactions more hydrodynamic. In the other hand, crushed sand gives less flowability to the SCC, due to the high intergranular friction between the different particles $>$ $0.125 \mathrm{~mm}$ [11]. Crushed sand needs more water to give the aimed workability; but also the nature of this sand (limestone) makes absorbs some amount of mixing water. This is to be discussed in further works.

Contrary to the rheological properties of fresh SCC, it has been shown that crushed sand has better contribution to the strength development, especially in the case of tensile strength. Dune sand needs more past to cover its fine particles.

In both fresh and hardened SCC properties, the association of dune and crushed sands gives better results than mixtures with only one kind of sand. Dune sand alone gives high slump-flow, but not as high as in case of mixtures with both kinds of sands. This is due to the fine particles of dune sand which reduce the concrete workability .

\section{Acknowledgments}

The authors would like to thank all persons who ensured the good running of experiments in the laboratory of construction materials, University of M'sila, Algeria.

\section{References}

[1] G. Ye, X. Liu, G. de Schutter, A. M. Poppe and L. Taerwe, Influence of limestone powder used as filler in SCC on hydration and microstructure of cement pastes, Cement \& Concrete Composites 29 (2007) 94-102.

[2] E. Güneyisi and M. Gesoğlu, Properties of self-compacting mortars with binary and ternary cementitious blends of fly ash and metakaolin, Materials and Structures 41 (2008) 1519-1531.

[3] J. Hu and K. Wang, Effects of size and uncompacted voids of aggregate on mortar flow ability, Journal of Advanced Concrete Technology 5 (1) (2007) 75-85.

[4] M. Geiker, R. M. Brandl, L. N. Thrane and L. F. Nielsen, On the effect of coarse aggregate fraction and shape on the rheological properties of self-compacted concrete, Cement, Concrete and Aggregate 24 (1) (2002) 3-6.

[5] The Self-Compacting Concrete European Project Group, The European Guidelines for Self Compacting Concrete-Specification, Production and Use, May 2005, p. 63.

[6] H. J. Brouwers and H. H. J. Radix, Self-compacting concrete: Theoretical and experimental study, Cement and Concrete Research 35 (2005) 2116-2136.

[7] K. Audenaert, V. Boel and G. D. Schutter, Carbonation of self compacting concrete, in: Proceeding of the 6th International Symposium on High Strength/High Performance Concrete, Leipzig, June 2002, pp. 835-862.

[8] H. Okamura and M. Ouchi, Self-compacting concrete, Journal of Advanced Concrete Technology 1 (1) (2003) $5-15$.

[9] A. S. Al-Harithy, M. Abdel Halim, R. Taha and K. S. Al-Jabri, The properties of concrete made with fine dune sand, Construction and Building Materials 21 (2007) 1803-1808.

[10] Z. Benghazi, The effect of mineral admixtures on the properties of activeted slag cement. Magister Thesis, Department of Civil Engineering, University of M'sila, Algeria, 2008, p. 110. (in French)

[11] J. Yammine, M. Chaouche, M. Guerinet, M. Moranville and N. Roussel, From ordinary rheology concrete to self compacting concrete: A transition between frictional and hydrodynamic interactions, Cement and Concrete Research 38 (2008) 890-896. 